\title{
Assessment of the Mechanical Properties of Bagasse Ash Concrete
}

\author{
Amanuel Bersisa*, Adil Zekaria \\ Civil and Environmental Engineering, Addis Ababa Institution of Technology, Addis Ababa, Ethiopia \\ Email address: \\ amanuel.bersisa@aait.edu.et (A. Bersisa), adil.zekaria@aait.edu.et(A. Zekaria) \\ ${ }^{*}$ Corresponding author
}

To cite this article:

Amanuel Bersisa, Adil Zekaria. Assessment of the Mechanical Properties of Bagasse Ash Concrete. Engineering Science. Vol. 6, No. 3, 2021, pp. 39-44. doi: 10.11648/j.es.20210603.12

Received: July 17, 2021; Accepted: August 3, 2021; Published: August 12, 2021

\begin{abstract}
Sugarcane bagasse ash is found abundantly in Ethiopia. Researchers in the area focus to sustainably use this pozzolan as a raw material for concrete production. This study aims to investigate the early and late age mechanical properties of Bagasse ash concrete. Concrete mixtures containing pure Portland cement, $6.5 \%, 13 \%$, and $20 \%$ dosage of Bagasse ash by volume were proportioned. The compressive, tensile, flexural strength data at one, two, three, seven, twenty-eight days are determined. The experimental outcomes indicate that the tensile strength of bagasse ash concrete for $6.5 \%$ and $13 \%$ replacement ratio dropped by $6.98 \%$ and $22.5 \%$ compared to full cement concrete at three days of testing. As well, there is a reduction of third-day flexural strength by $5.96 \%$ and $13.1 \%$. In advance, the 28 th-day flexural strength increased by $6.38 \%$ and $17.02 \%$ for $6.5 \%$ and $13 \%$ replacement ratio. The compressive strength of bagasse ash concrete with $6.5 \%$ and $13 \%$ replacement ratios exceed the control group's 28 th-day strength by $3.46 \%$ and $6.64 \%$ sequentially. Possibly, the ettringite formed as the base solution reacts with metallic oxides densifies the interfacial transition zone. Bagasse ash also contains inert unburned carbon particles that will fill the voids of hardened concrete. On the other hand, replacing cement with bagasse ash up to $20 \%$ reduces both the early and late age flexural strength and tensile strength development of concrete.
\end{abstract}

Keywords: Bagasse Ash, Pozzolan, Early Age Strength, Waste Management, Sustainable Concrete

\section{Introduction}

Cement production is the third-largest source of anthropogenic emission of carbon dioxide, which covers up to $5 \%$ of the total amount $[1,2]$. Similarly, the by-product of industries is resulting in environmental pollution [3]. Therefore, it has become necessary to provide sustainable solutions to waste and solve it. Researchers are centering on ways of utilizing industrial waste as raw material for the construction industry. Fly ash, Coal ash, Blast furnace slag, and Bagasse ash are waste materials that possess a pozzolan property because of the high silica content in their chemical compositions.

These industry wastes could be potential partial cement replacement materials. Utilizing such wastes as cement replacement materials may reduce the cost of concrete production and minimize its negative impact on the environment [3-5]. There are thirteen sugar projects (fully completed and in production, and partially completed) in Ethiopia. In sugar production, the extraction of juice from sugarcane will leave fibrous material known as Bagasse. Most sugar industries use the residue as fuel in boilers to generate electricity. After the Bagasse is burned in the boiler, the ash will be damped nearby as a waste [6]. The ashes contain a high amount of metallic oxide and loss of ignition. After checking the ash chemical composition and the silica content, studies recommend using bagasse ash as a cement replacement material will improve quality and reduce concrete production costs $[7,8]$.

Srinivasan and Sathiya [7] had carried out experimental studies with different Bagasse ash to cement replacement ratios to examine mechanical properties. The study states that the $10 \%$ replacement ratio was optimum to gain relatively low weight concrete with good mechanical properties. It is signposted to use Bagasse ash up to $20 \%$ but with a slight reduction in strength. Reddy et al. [9] blended bagasse ash in a concrete mixture and checked its performance after exposing it to magnesium sulfate solution. The study revealed that, up to $15 \%$ replacement level, the Bagasse ash ensured the desired strength and increased the resistivity towards sulfate attack. According to Suliman and 
Amola [10], Bagasse ash acts as a class F fly ash, and its reactive silica content varies from 56.7-58.02\%. Bagasse is a non-volatile, incombustible, and thermally altered mineral. Srinivasan and Sathiya [7] reported the three-oxide components $\left(\mathrm{SiO}_{2}, \mathrm{Al}_{2} \mathrm{O}_{3}\right.$, $\mathrm{Fe}_{2} \mathrm{O}_{3}$ ) found in bagasse ash account for more than $75 \%$ of the total mineral content. Besides, the loss of ignition (LOI) was within the limit indicated in the ASTM C 618-00 manual.

Studies are also undertaken using Ethiopian sugar factories bagasse ash. Geremew [11] has studied the appliance of bagasse ash to lower the heat generation in the rigid pavement. $10 \%$ replacement ratio was optimum to enhance the compressive strength by $1.23 \%$ and reduce the total heat of hydration by $20.28 \%$. Similarly, Biruk [12] revealed that cement advantageously is replaced up to $10 \%$, but the $15 \%$ and $25 \%$ replacements have shown $3.4 \%$ and $12.6 \%$ reduction of strength at 28 days of testing.

Although most of the studies on the utilization of pozzolan focus on the late age compressive strength development, this study is carried out to examine the flexural and splitting tensile strength adjacent to the compressive strength. The strength development at one, two, three, seven, and twenty-eight days have been checked. Indeed, this helped to get the whole picture of strength development.

\section{Material and Methods}

\subsection{Materials}

Fine and Coarse Aggregate: The physical properties of coarse and fine aggregate are tested according to ACI and ASTM standards at the Addis Ababa University construction material laboratory. The physical characterization includes specific gravity, bulk unit weight, gradation, silt content, etc.

Table 1. Coarse and Fine Aggregate Physical Properties.

\begin{tabular}{llll}
\hline Property & Standard & Fine Aggregate & Coarse Aggregate \\
\hline Fineness Modules & ASTM C 136 84 & 2.61 & - \\
Nominal Aggregate size & ASTM D 448 - 98 & - & $25 \mathrm{~mm}$ \\
Dry Rodded Unit Weight & ASTM C 29-97 & $1524.39 \mathrm{~kg} / \mathrm{m}^{3}$ & $1598.65 \mathrm{~kg} / \mathrm{m}^{3}$ \\
Bulk SG & ASTM C 127 - 88 & 2.41 & 2.75 \\
Absorption Capacity & ASTM C 127 - 88 & 2.74 & 1.52 \\
Moisture Content & ASTM C 566- 84 & 1.62 & 0.81 \\
\hline
\end{tabular}

Cement: The cement material is Type- 1 Portland cement (42.5-N) from the Dangote cement factory.

Bagasse Ash: The ash used for the study is collected from a sugar mill located in Wonji. It was left to dry for a certain amount of time and filtered using a $300-\mu \mathrm{m}$ sieve to remove the unwanted materials. The specific gravity of cement and bagasse ash determined according to ASTM C188-17 standard procedures gave values 3.15 and 2.14 respectively. The surface area of the bagasse ash is determined according to ASTM 2 204-00 using the Blaine air-permeability apparatus gave a value of $3177.3 \mathrm{~cm}^{2} / \mathrm{g}$. Moreover, with the help of Ethiopian geological and survey, a complete silica analysis experiment is conducted. The results are reported in figure 1.

The local Bagasse ash satisfies the criteria specified in ASTM-C 618-00 (standard specification for coal fly ash and raw or calcined natural pozzolan for use as a mineral admixture in concrete). This local pozzolan possesses higher silica content, and it is grouped under Class-F pozzolan material.

Bagasse Ash

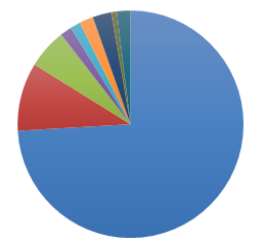

$$
\mathrm{SiO} 2
$$$$
\mathrm{A12O3}
$$$$
\square \mathrm{Fe} 2 \mathrm{O3}
$$$$
\because \mathrm{CaO}
$$$$
\mathrm{SiO}_{2}+\mathrm{Al}_{2} \mathrm{O}_{3}+\mathrm{Fe}_{2} \mathrm{O}_{3}
$$$$
=83.18>75
$$

$\square \mathbf{K 2 O}$

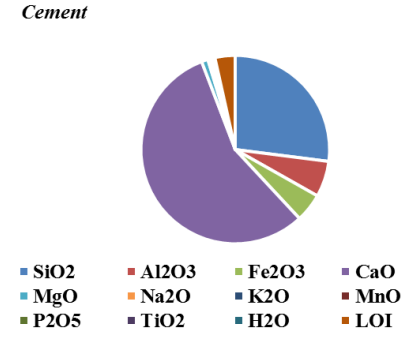

(b)

Figure 1. Chemical Composition of Cement and Bagasse ash.

\subsection{Mixture Design}

ACI 211.1-91 standard procedure is adopted for the mixture design. The control group mix proportion was $25 \mathrm{MPa}$ specified compressive strength or $33 \mathrm{MPa}$ target average compressive strength. The quantity of materials for the control group is summarized in table 2 .

Table 2. Summary of Mix-design.

\begin{tabular}{lll}
\hline No. & Material & Weight of material $\left(\mathbf{k g} / \mathbf{m}^{\mathbf{3}}\right)$ \\
\hline 1 & Water & 190 \\
2 & Cement & 334.51 \\
3 & Coarse aggregate & 1046.52 \\
4 & Fine aggregate & 763.03 \\
\hline
\end{tabular}

Replacement of cement by pozzolan can be weight or volume-based. The weight-based approach will not form equal paste volume for different mix proportions. Volume-based replacement is selected for this study to create a fixed paste volume within all mix proportions. According to 
ACI 211.1-91, the relationship between the weight and volume of pozzolan is related by equation 1 .

$$
F w=\frac{1}{1+\left(3.15 / \mathrm{G}_{\mathrm{p}}\right)\left(\frac{1}{\mathrm{f}_{\mathrm{v}}}-1\right)}
$$

Where: $F_{w}=$ Weight of pozzolan

$\mathrm{G}_{\mathrm{p}}=$ Specific gravity of pozzolan

$\mathrm{f}_{\mathrm{v}}=$ Percentage volume replacement level

Table 3. Quantity of Bagasse Ash for Each Replacement Level.

\begin{tabular}{|c|c|c|c|c|}
\hline Mixture Id. & Replacement Level (\%) & Weight of Bagasse ash $\left(\mathrm{kg} / \mathrm{m}^{3}\right)$ & Weight of Cement $\left(\mathrm{kg} / \mathrm{m}^{3}\right)$ & Water/Binder (By Weight) \\
\hline BA-0 & 0 & 0 & 334.51 & 0.57 \\
\hline BA- 6.5 & 6.5 & 15.08 & 312.76 & 0.58 \\
\hline BA-13 & 13 & 30.82 & 291.02 & 0.59 \\
\hline BA-20 & 20 & 48.36 & 267.6 & 0.60 \\
\hline
\end{tabular}

Where: - BA- $0=$ Control group with 100\% OPC, BA: Bagasse Ash, OPC: Ordinary Portland Cement

BA-6.5=Mixture with $6.5 \%$ of bagasse ash and $93.5 \%$ OPC, *The Water/Binder Ratio in Volume based is Constant (0.56)

BA-13=Mixture with $13 \%$ of bagasse ash and $87 \%$ OPC

BA- $20=$ Mixture with $20 \%$ of bagasse ash and $80 \%$ OPC

Since the weight of the total binder decrease due to increment in Bagasse ash replacement level, the water to binder ratio (in weight basis) will increase to some extent, as shown in table 3 .

\subsection{Test Setup and Procedure}

\subsubsection{Mixing, Vibrating, and Curing Condition}

The mixing process was following the ASTM C-192 requirement. The mixing machine is lubricated with water to prevent it from absorbing the mixture water. After the ingredients were mixed for 3 minutes, it was left to rest for 3 minutes, followed by $2 \mathrm{~min}$ final mixing. The slump of each freshly mixed concrete was measured using ASTM C-143 procedure. Filling the mortar into the mold is done using a scoop and shovel. The molds were half-filled, vibrated by a vibrating table, and then poured to top-level and shaken again for $30 \mathrm{sec}$. The molds are kept on a rigid surface to avoid any disturbance. The specimens were removed from the mold after 24 hours and were kept in a water container at room temperature. The samples were taken out from the water tank one day before testing.

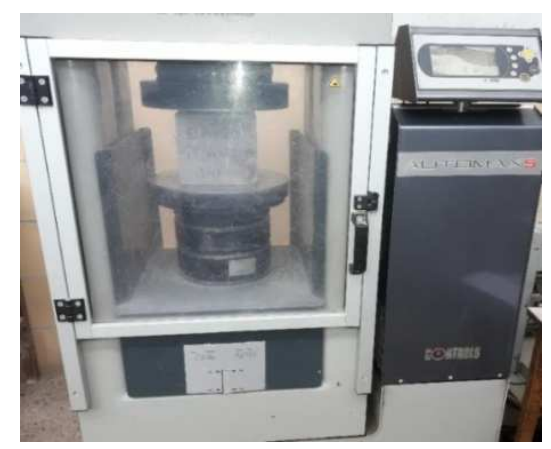

Figure 2. Compressive strength experiment.

\subsubsection{Mechanical Properties}

Compressive Strength: was determined using $15 \mathrm{~cm} * 15 \mathrm{~cm} * 15 \mathrm{~cm}$ cubical concrete cores. The strength check is conducted on One, Two, Three, Seven, and Twenty-Eight days. This test method involves a compressive axial load at a loading rate of $0.15-0.3 \mathrm{MPa} / \mathrm{sec}$ to the samples until failure occurs (ASTM C-39). The stress on the specimen is calculated by dividing the ultimate load by its cross-sectional. The universal compression-testing machine used in this study is capable of determining both the failure load and stress.

Splitting Tensile Strength: This method involves applying a diametric compressive force along the length of a cylindrical concrete specimen at a loading rate of $689 \mathrm{KPa} / \mathrm{min}-1380$ $\mathrm{KPa} /$ min until failure occurs (ASTM C-496-71). The tensile stress is calculated in equation 2 (ASTM C-496-71).

$$
\sigma=\frac{2 * P}{\pi D L}
$$

Where: P: Applied load at failure

D: Diameter of cylinder

L: Length of the cylinder

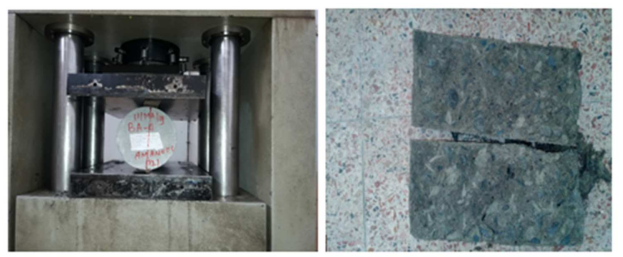

Figure 3. Splitting Tensile Strength Experiment.

Figure 3 shows the test setup of the splitting tensile strength experiment. The figure shows the concrete specimen is crushed in two equal parts, and it is evidence that the sample fails due to tension force.

Flexural Strength: ASTM C 78-00 standard procedure is used to examine the flexural capacity. A three-point bending test is conducted on a loading frame to determine the flexural tensile strength on common beam specimens of size $50 \mathrm{~cm} \times$ $10 \mathrm{~cm} \times 10 \mathrm{~cm}$. The flexural strength can be calculated using the following equation (ASTM C 78-00).

$$
\sigma=\frac{F L}{W D^{2}}
$$

Where: - F: Failure load

L: The length of the specimen

$\mathrm{W}$ : the width of the specimen

D: the depth of specimen. 


\section{Result and Discussion}

\subsection{Fresh Property of Concrete}

Optimization of pozzolan in concrete mixture affects the workability of concrete. Therefore, the average slump value for each replacement level is checked and summarized in table 4 .

Table 4. Average slump value.

\begin{tabular}{llll}
\hline Mixture Id. & $\begin{array}{l}\text { Replacement } \\
\text { Level (\%) }\end{array}$ & Water/Binder & $\begin{array}{l}\text { Average Slump } \\
\text { Value (mm) }\end{array}$ \\
\hline BA-0 & 0 & 0.57 & 52 \\
BA-6.5 & 6.5 & 0.58 & 38 \\
BA-13 & 13 & 0.59 & 29 \\
BA-20 & 20 & 0.60 & 20 \\
\hline
\end{tabular}

There was a loss of workability when the replacement level increase. Replacing cement with $13 \%$ and $20 \%$ of bagasse ash reduced the average slump value by $44 \%$ and $61 \%$ respectively. The physical features and LOI of bagasse ash could cause this situation. According to Hailu [12], the bagasse ash possesses a higher specific surface area, so great water is needed to lubricate it. To get workability, concrete with SCBA needs higher water content than concrete without SCBA [13].

Moreover, bagasse ash contains lightweight, porous, fibrous carbon particles [14, 15]. It will lead to an absorption of mixing waters and result in a dry mix. High LOI also leads to a greater water demand, which means reducing LOI could improve workability [16]. In contrast, some study indicates that SCBA increases fresh concrete workability [7, 17-19].

\subsection{Hardened Concrete Properties}

In addition to the ultimate strength, the strength development starting from an early age matters a lot. According to building codes, a structure should withstand a construction load before it is fit to serve the intended purpose. Concrete structures under construction might not meet their ultimate strength, and examine their behavior at an early age is crucial. For instance: on mass concrete structures, the early age strength has a significant impact against thermal cracking. This study tried to capture the strength development of different concrete mixtures starting from day-1. For each blend, three specimens were tested, and the average results are graphically presented.

\subsubsection{Compressive Strength}

Although the reduction in early age compressive strength development is observed, the compressive strength of bagasse ash concrete with $6.5 \%$ and $13 \%$ replacement ratios exceed the control group 28th day strength by $3.46 \%$ and $6.64 \%$ respectively (see figure 4 ). The pozzolan reaction depends on the hydration of cement particles. Bagasse ash is an inert material until it gets a base solution from the hydration of cement. Thus, the reason for a drop in compressive strength at an early age is that enough calcium hydroxide (base solution) could not be available for the nonce.

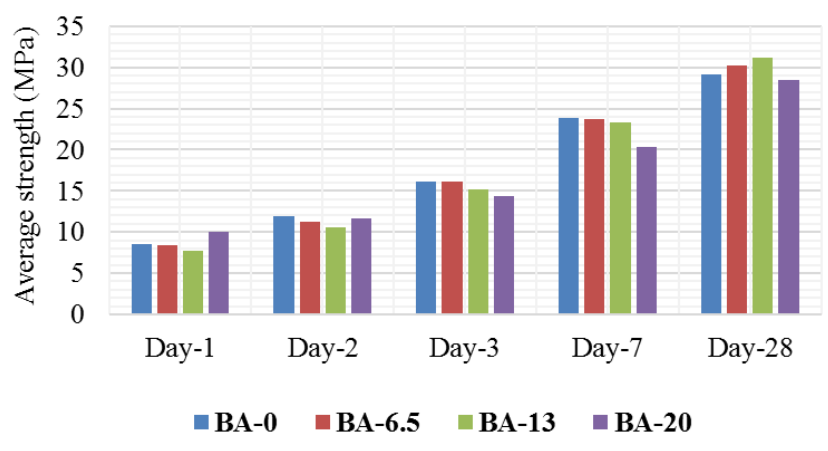

Figure 4. Compressive Strength Development.

Moreover, the replacement of cement by SCBA would decrease the contents of $\mathrm{C}_{3} \mathrm{~A}$ and $\mathrm{C}_{3} \mathrm{~S}$; those chemical compositions are responsible for early-age strength development. The blending of bagasse ash also takes the mixing water and leads the cement to lack water for hydration [13]. As the hydration keeps going, the calcium hydroxide will be available reasonably for the pozzolan reaction, ensuring ultimate strength development.

The additional strength gains over time resulted from the reaction between pozzolan material and calcium hydroxide. The pozzolan has a contribution to facilitate the normal hydration process. Neville [20] states, after cement complexes react with water (E.g., $\mathrm{C}_{3} \mathrm{~S}$ ), calcium hydroxide (a byproduct of hydration) will act as a thin film around the remaining cement compounds like $\mathrm{C}_{2} \mathrm{~S}$, and it will alter leftover chemical reactions. The introduced bagasse ash absorbs calcium hydroxide solution from hydration products. It helps to resume the hydration process and ensures ultimate strength development.

\subsubsection{Splitting Tensile Strength}

The tensile strength is the essential property of concrete directly interrelated with early-age thermal cracking. Although premature failure is considered a drawback of splitting tensile experiments, it has not occurred in this study.

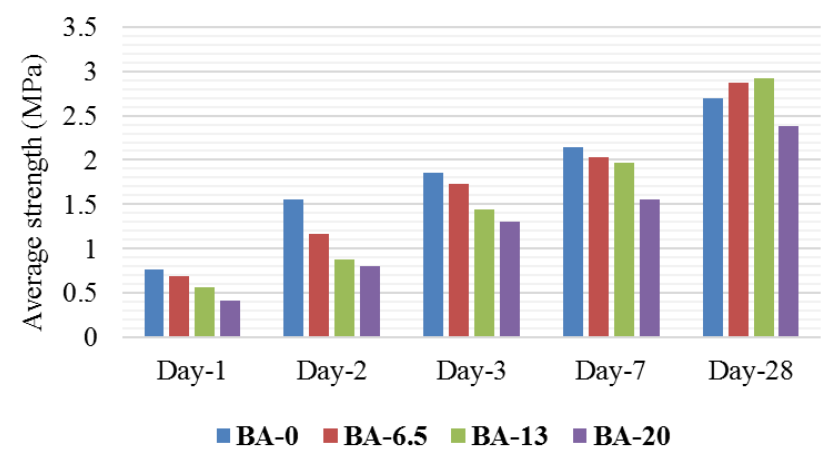

Figure 5. Tensile Strength Developments.

Figure 5 shows that the tensile strength also enhances with time. Looking at late-age strength development, replacing cement using $6.5 \%$ and $13 \%$ of bagasse ash has ensured the desired strength (Control group). According to Mehta and Monteiro [21], micro-cracking originates in the Interfacial transition zone (ITZ), and cracking develops as the load is applied. Empty voids are formed in ITZ while water escapes 
from the large aggregate surface in the form of bleeding. The progress of hydration (C-S-H formation) will eventually fill those empty voids and densify the ITZ. Rossignolo et al. [22] have evaluated the influence of industrial sugarcane ash on the mechanical properties of ITZ by Nano-indentation technical analysis. The outcome verified that SCBA causes a similar and significant reduction in the matrix-aggregate ITZ thickness compared to the reference concrete. As the thickness of ITZ decreases, the interface region's microstructure enhances. Optimizing bagasse ash in concrete mixture up to $13 \%$ replacement level will further enhance tensile strength due to the substitution of weak calcium hydroxide layer found in the ITZ by a more densified ettringite. This replacement is the optimum value as further increase the replacement level has remarkably decrease the strength.

However, a remarkable early age tensile strength drop has occurred on concrete samples containing bagasse ash (See figure 5). The strength of bagasse ash concrete for $6.5 \%$ and $13 \%$ replacement ratio is dropped by $6.98 \%$ and $22.5 \%$ compared with the control group at three days of testing. According to chemical characterization, the local bagasse ash takes Class-F Fly ash property. Class-F Fly ash does not possess self-hardening behaviour like Class-C Fly ash, and the pozzolanic activity depends on the hydration of cement [23]. Thus, mixtures contain this pozzolan show a reduction in early age splitting strength.

\subsubsection{Flexural Strength}

As shown in figure 6, the flexural strength of concrete samples contains $6.5 \%$, and $13 \%$ of bagasse ash offers a relatively higher value than the control group in the late testing age. The 28th-day flexural strength is increased by $6.38 \%$ and $17.02 \%$ for $6.5 \%$ and $13 \%$ replacement ratio. In contrast, a reduction of third-day flexural strength by $5.96 \%$ and $13.1 \%$ is observed. On the other hand, replacing cement with bagasse ash up to $20 \%$ reduces concrete's early and late age flexural strength development.

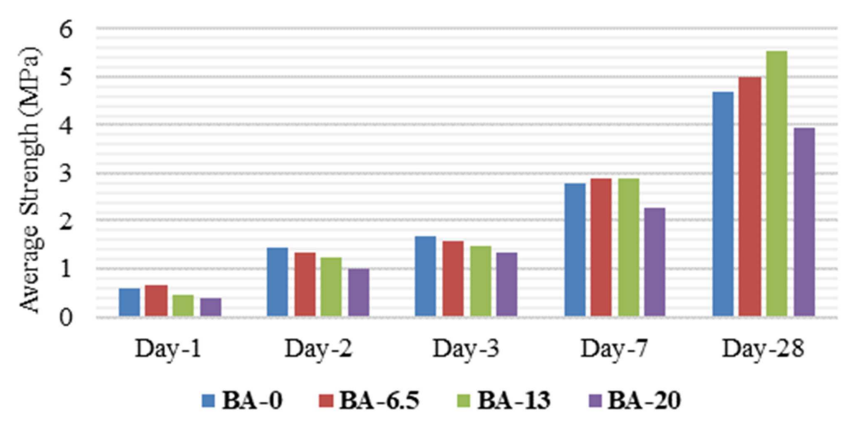

Figure 6. Flexural Strength Developments.

Portlandite (Calcium hydroxide) constitutes 20 to 25 percent of the volume of solids in the hydrated paste. The strength contributing potential of Portlandite is limited because of the considerably lower surface area [21]. The presence of bagasse ash in the hydrated paste undergoes a chemical reaction with calcium hydroxide to create additional $\mathrm{C}-\mathrm{S}-\mathrm{H}$ and needle-shaped prismatic crystals (ettringite). Concrete strength might be affected by a delayed ettringite formation (DEF). DEF result cracks result in a decrease in the mechanical performance and durability parameters of the material. The use of bagasse ash in partial substitution of cement could mitigate DEF and improve the concrete strength [24].

The flexural and splitting tensile strength experiments are indirect methods used to assess the tensile capacity of concrete. Splitting tensile experiments have a drawback due to pre-mature failure, which uneven distribution of stress under radial compressive force makes this method disadvantageous. Similarly, flexural tensile strength is affected by the level of stress, size, age, and confinement to concrete flexure members. The present study tried to compare the two approaches.

The control group's 28th-day flexural tensile strength is exceeded by $42 \%$ from the splitting tensile strength. Similarly, the splitting tensile strength of concrete specimens contains $6.5 \%$ and $13 \%$ of bagasse ash is less by $42.6 \%$ and $47.3 \%$ from the flexural tensile capacity sequentially. It indicates, the flexural tensile experiment overestimates the tensile strength of concrete specimens.

\section{Conclusion}

From the above experimental work, the following points are drawn.

1) Blending bagasse ash in a concrete mixture remarkably affects the workability of the mix.

2) The addition of bagasse ash in a concrete mixture has reduced concrete specimens' early age mechanical performance.

3) The compressive strength of bagasse ash concrete with $6.5 \%$ and $13 \%$ replacement ratios exceed the control group's 28th-day strength by $3.46 \%$ and $6.64 \%$ respectively..

4) The splitting tensile strength of bagasse ash concrete for $6.5 \%$ and $13 \%$ replacement ratio is dropped by $6.98 \%$ and $22.5 \%$ compared to the control group at three days of testing.

5) The early day's flexural strength dropped significantly for 6.5 and $13 \%$ replacement ratio comparing with the control group. In addition, usage of bagasse ash by $6.5 \%$ and $13 \%$ replacement ratio enhanced the strength by $6.38 \%$ and $17 \%$ on the 28 th day.

6) The flexural tensile experiment overestimates the tensile capacity of concrete specimens. For instance, the control group's 28th-day flexural tensile strength is exceeded by $42 \%$ from the splitting tensile strength.

\section{Recommendation}

The research is limited to the mechanical properties of bagasse ash concrete. Future studies should focus on the durability mechanics (Creep, Shrinkage, Corrosion, etc.) of concrete contain this Pozzolan. Moreover, with the aid of Scanning Electron Microscopy (SEM) and X-Ray Diffraction (XRD), the microstructure could be examined to see the interactions between bagasse ash and the cement at different hydration levels. The contribution of bagasse ash in reducing 
DEF could also be a potential area for future works.

\section{Acknowledgements}

The Authors are very grateful to Addis Ababa University and Dr. Esayas Gebreyohannes for the provided technical support. We are also appreciative to Wonji and Metehara Sugar factories for providing the SCBA.

\section{References}

[1] Raja, Krovvidi Bangar. 2015. "Behaviour of Sugarcane Bagasse Ash Concrete When Exposed to Various Temperature and Cooled at Room Temperature," no. December.

[2] Mikulić, D., B. Milovanović, and I. Gabrijel. 2012. “Analysis of Thermal Properties of Cement Paste during Setting and Hardening." RILEM Bookseries 6: 465-71. https://doi.org/10.1007/978-94-007-0723-8_66.

[3] Abdulkadir, T., D. Oyejobi, and A. Lawal. 2014. "Evaluation of Sugarcane Bagasse Ash As a Replacement for Cement in Concrete Works.” ACTA TEHNICA CORVINIENSIS-Bulletin of Engineering 3: 71-76.

[4] Agrawal, Dhiraj, Pawan Hinge, U P Waghe, and S P Raut. 2007. "Utilization of Industrial Waste in Construction Material - A Review." International Journal of Innovative Research in Science, Engineering and Technology (An ISO Certified Organization) 3297 (1): 8390-97. www.ijirset.com.

[5] Cabrera, H, C Daza, C Pacheco-Bustos, and M Murillo. 2021. "Study on Mechanical Properties of Mortars Containing Steel Shot and Sea Sand as Fine Aggregate Replacement." IOP Conference Series: Materials Science and Engineering 1126 (1): 012003. https://doi.org/10.1088/1757-899x/1126/1/012003.

[6] Narain Das Bheel, Santosh Kumar Meghwar, Rameez Ali Abbasi, Israr Ahmed Ghunio, Zubair Hussain Shaikh. 2020. "Use of Sugarcane Bagasse Ash as Cement Replacement Materials in Concrete." E 4th International Conference on Sustainable Innovation 2020 -Technology, Engineering and Agriculture (ICoSITEA 2020) 199 (February): 144-50.

[7] Srinivasan, R, and K Sathiya. 2010. "Experimental Study on Bagasse Ash in Concrete." International Journal for Service Learning in Engineering, Humanitarian Engineering and Social Entrepreneurship 5 (2): 60-66. https://doi.org/10.24908/ijsle.v5i2.2992.

[8] Mahmud, Safayat, Md. Imamul Islam, Rubieyat Bin Ali, Md. Mofizul Islam, and Md. Mahadi Hasan. "Compressive Behaviour of Concrete by Using Bagasse Ash From Sugar Mill." Journal of Science and Technology 10, no. 3 (December 1, 2018). doi: 10.30880/jst.2018.10.03.008.

[9] Reddy, G. Nithin Kumar, G. Harsha Vardhan, and S. Vijaya Bhaskar Reddy. 2016. "Partial Replacement of Cement in Concrete with Sugarcane Bagasse Ash and Its Behaviour in Aggressive Environments." IOSR Journal of Mechanical and Civil Engineering $16 \quad$ (053): 29-35. https://doi.org/10.9790/1684-16053012935.

[10] Suliman, Mohamed Eljack, and Samah M Fudl Amola. 2011. "The Use of Sugarcane Bagasse Ash As an Alternative Local Pozzolanic Material: Study of Chemical Composition." Science Vision 16 (December): 65-70.
[11] Geremew, Miheret. 2017. "Bagasse Ash as a Partial Substitute of Cement on Concrete Rigid Pavement." Addis Ababa University.

[12] Hailu, Biruk. 2011. "Bagasse Ash as a Cement Replacing Material." Addis Ababa University. https://doi.org/10.13140/RG.2.1.2257.8166.

[13] Vishnumaya, L, and Ambi Rekha. 2015. "Strength and Durability of OPC-Fly Ash-Sugarcane Bagasse Ash Blended Concrete" 5 (7): 436-41.

[14] Bahurudeen, A., and Manu Santhanam. 2015. "Influence of Different Processing Methods on the Pozzolanic Performance of Sugarcane Bagasse Ash." Cement and Concrete Composites 56 : $32-45$. https://doi.org/10.1016/j.cemconcomp.2014.11.002.

[15] Schettino, Myrian Aparecida S., and José Nilson F. Holanda. 2015. "Characterization of Sugarcane Bagasse Ash Waste for Its Use in Ceramic Floor Tile." Procedia Materials Science 8: 190-96. https://doi.org/10.1016/j.mspro.2015.04.063.

[16] Xu, Qing, Tao Ji, San Ji Gao, Zhengxian Yang, and Nengsen Wu. 2018. "Characteristics and Applications of Sugar Cane Bagasse Ash Waste in Cementitious Materials." Materials 12 (1): 1-19. https://doi.org/10.3390/ma12010039.

[17] Pramoth, G, Karunya Devi G, and A Murugesan. 2020. "Experimental Study on Using Bagasse Ash in Concrete and Curing With Different Types of Water," no. July: 802-7.

[18] Mangi, Sajjad Ali, N. Jamaluddin, M. H. Wan Ibrahim, Abd Halid Abdullah, A. S. M. Abdul Awal, Samiullah Sohu, and Nizakat Ali. 2017. "Utilization of Sugarcane Bagasse Ash in Concrete as Partial Replacement of Cement." IOP Conference Series: Materials Science and Engineering 271 (1). https://doi.org/10.1088/1757-899X/271/1/012001.

[19] Rahman Sobuz, Habibur, Noor Md. Sadiqul Hasan, Nafisa Tamanna, and Md. Saiful Islam. "Structural Lightweight Concrete Production by Using Oil Palm Shell." Journal of Materials 2014 (March 20, 2014): 1-6. doi: $10.1155 / 2014 / 870247$.

[20] Neville, Adam M. 2011. The Properties of Concrete. Pearson Education Limited. $5^{\text {th }}$ edition. Vol. 65. Pearson Education Limited. https://doi.org/10.11129/detail.9783034614740.19.

[21] Mehta, P. Kumar, and Paulo J. M. Monteiro. 2006. Microstructure, Properties, and Materials. Third Edit. New York: McGraw-Hill. https://doi.org/10.1036/0071462899.

[22] Rossignolo, João Adriano, Michelle Santos Rodrigues, Moises Frias, Sérgio Francisco Santos, and Holmer Savastano Junior. 2017. "Improved Interfacial Transition Zone between Aggregate-Cementitious Matrix by Addition Sugarcane Industrial Ash." Cement and Concrete Composites 80: 157-67. https://doi.org/10.1016/j.cemconcomp.2017.03.011.

[23] Rafat Siddique, Mohammad Iqbal Khan. 2011. Supplementary Cementing Materials. Developments in the Formulation and Reinforcement of Concrete. Berlin: Springer. https://doi.org/10.1016/B978-0-08-102616-8.00003-4.

[24] Nguyen, Van Huong, Nordine Leklou, Jean Emmanuel Aubert, and Pierre Mounanga. 2013. "The Effect of Natural Pozzolan on Delayed Ettringite Formation of the Heat-Cured Mortars." Construction and Building Materials 48: 479-84. https://doi.org/10.1016/j.conbuildmat.2013.07.016. 